\title{
The Acute Dying Experience
}

\author{
Michael B. Sabom, M.D. \\ Atlanta, GA
}

\begin{abstract}
The acute dying experience (ADE) incorporates peritraumatic dissociation and hyperarousal (for example, speeding thought, narrowing and sharpening of perception, and preparation for action) into an experiential continuum lasting seconds to minutes. It is instantly triggered by the sudden, clear perception of threat of significant injury and/or death and followed, at times, by physical trauma, physiological derangement, and loss of consciousness. Peritraumatic dissociation was diagnosed in 83 percent of survivors of 52 life-threatening accidents. Depth of peritraumatic dissociation correlated positively with subject's severity of injury $(p<.05)$, loss of consciousness $(p<$ $.05)$, perceived certainty of death $(p=.055)$, and hospital treatment $(p=.10)$. Eighty-four percent of injured subjects felt no immediate pain regardless of severity of injury. Absence of emotion accompanied minor injury; a feeling of peace predominated with more severe trauma. The ADE mirrors the threephase response of perception, defense, and recuperation observed during predator-prey interaction in animals. It appears to be an adaptive response that promotes survival by holding paralyzing emotions in abeyance, increasing mental alertness, and blocking disabling pain. Results from this and other studies show that paradoxically the more terrifying and traumatic an accident may appear, the more peaceful and painless it may actually be experienced.
\end{abstract}

KEY WORDS: acute dying experience; peritraumatic dissociation; hyperarousal; adaptive response; endorphins.

"If when directly before the gate of death, consciousness flashes up in marvelous fiery ardour, like a mountain peak before the fall of night, it does so not from a singular perfection of power or highest ideational creation, but rather from a quiet experience that passivity of feeling fills with the highest aesthetic values."

Oskar Pfister, 1930, trans. in R. Kletti and R. Noyes,1981, p. 18

Michael B. Sabom, M.D. is a cardiologist in private practice. He gratefully acknowledges the assistance of Russell Noyes, M.D. in the preparation of this manuscript. Reprint requests should be sent to Dr. Sabom at 100 Wing Mill Road, Atlanta, GA 30350; email: MSabom2@aol.com. 
The DC-10 had lost all hydraulics and the pilots on United Air Lines Flight 232 had only the power of the left and right engines to control the aircraft as it approached Sioux City, Iowa, on July 19, 1989. According to the National Transportation Safety Board:

The aircraft approached with a high sink rate $(1620 \mathrm{feet} / \mathrm{min}$ for the last 20 seconds) at an airspeed of 215 knots. [Normal sink rate is $300 \mathrm{feet} /$ minute and airspeed 140 knots at touchdown in a DC-10.] At 100 feet above the ground the nose began to pitch downward and the right wing dropped. (http://aviation-safety.net/database/record. php?id = 19890719-1, accessed 04/17/07)

"Well, we started to go over. I was like, I don't want to do this. I know this airplane is starting to roll" recalled Jan Brown-Lohr, Senior Flight Attendant on Flight 232 (Survival in the Sky, 1996).

"The plane touched down on the threshold slightly left of the centreline, skidded to the right and rolled inverted. The DC-10 caught fire and cartwheeled" (http://aviation-safety.net/database/record.php?id= 19890719-1, accessed 04/17/07).

Brown-Lohr remembered these critical moments: "I couldn't hear anything, I couldn't feel anything, I couldn't smell anything, nothing was working except my mind; it was like total body detachment, or, or, being in a protective cocoon" (Survival in the Sky, 1996). The aircraft broke up, igniting into a huge fireball. Brown-Lohr reported that she

then realized that two-thirds of me was suspended in fire and I felt, this is, this is it, this is how I'm going to go, this is how I'm going to die, and it was the most incredibly peaceful moment Ive ever known, that I was in no pain. I had no fear anymore, it was total peace. (Survival in the Sky, 1996; emphasis added)

The burning wreckage came to rest upside down with the fuselage on its back. One hundred eleven people died by eventual count.

A recent review of the literature found limited research on the acute experience of dying, most studies having been conducted in people dying of chronic illness such as cancer (Kayser-Jones, 2002). These studies found that "depression, loneliness, fear, constipation, isolation, anxiety, edema, anorexia, insomnia and fatigue" frequently accompany the dying experience, despite modern medical advances (KayserJones, 2002, pp. 13-14). In the last three days of life, 40 percent of chronically ill patients suffer severe pain most of the time, 80 percent experience severe fatigue, and 63 percent have difficulty tolerating their physical or emotional symptoms (Lynn, Teno, Phillips, Wu, Desbiens, Harrold, Claessens, Wenger, Kreling, and Connors, 1997). 
As one 62-year-old woman dying of breast cancer put it: "Every part of my body hurts. . . . It's more painful than childbirth. It grabs on and won't go. . . Sometimes the pain is unbearable. . . It gets so bad that I try not to move. I get so tense! . . Dying is hard" (Kayser-Jones, 2002, p.13).

In contrast to the discomforting days to weeks of the chronic dying experience, dying acutely as in Brown-Lohr's case takes seconds to minutes and is reported to be "subjectively a very pleasant death" (Heim, 1892, trans. in Notes and Kletti, 1972, p. 51), accompanied by "emotionally comforting images" (Pfister, 1930, trans. in Kletti and Noyes, 1981, p. 6) that allow us "to face life's end with serenity, even acceptance" (Noyes and Kletti, 1976a, p. 27). This acute dying experience (ADE) consists of 2 main components: psychological dissociation and heightened arousal, which includes speeding thought, narrowing and sharpening perception, and preparation for action. It may be followed by a mystical or transcendental experience, that is, a near-death experience (Greyson, 1998), particularly in persons encountering "a more serious threat to life" (Noyes, 1979, p. 82) and "unconsciousness" (Sabom, 1982, p. 7; 1998, p. 32).

Dissociation is a cognitive and affective "disruption in the usually integrated functions of consciousness, memory, identity, or perception" (American Psychiatric Association, 2000, p. 519). Dissociation at the time a traumatic event is unfolding is defined by the new concept of peritraumatic dissociation, which

may take the form of altered time sense, with time being experienced as slowing down or rapidly accelerated; profound feelings of unreality that the event is occurring, or that the individual is the victim of the event; experiences of depersonalization; out-of-body experiences; bewilderment, confusion, and disorientation; altered pain perception; altered body image or feelings of disconnection from one's body; tunnel vision; and other experiences reflecting immediate dissociative responses to trauma. (Marmar, 1997, p. 1)

Psychological instruments have been developed to measure peritraumatic dissociation (Marmar, Weiss, Schlenger, Fairbank, Jordan, Kulka, and Hough, 1994).

These two components of the ADE occur within an experiential continuum lasting seconds to minutes beginning with sudden, clear perception of threat of significant injury and/or death and followed, at times, by physical trauma, physiological derangement, and loss of consciousness. It is not a near-death experience (NDE) as currently defined in that it is not transcendental or mystical (Greyson, 1998, p. 
14). Some who have ADEs may also have NDEs, but that involves an extension or something more. ADEs include peritraumatic dissociation, but is more than that, since hyperarousal is not part of this dissociative response. Peace and painlessness commonly occur during the experience, followed by overwhelming emotion and pain after the threat has passed. It has adaptive potential in the acute situation, but this potential may later be overwhelmed and lead to psychiatric disorders, such as acute stress disorder or posttraumatic stress disorder. Thus, the $\mathrm{ADE}$ is a subjective response to threat of death including dissociation and hyperarousal that, with the removal of the threat, is replaced by delayed emotional and cognitive response to the threat.

This essay examines this new concept of the ADE as experienced by survivors of life-threatening or serious accidents. I will discuss adaptive aspects of peritraumatic dissociation in relation to the perceptual-defensive-recuperative response to threat observed in animals during predator-prey interaction (Bolles and Fanselow, 1980). Results show that the emotional, psychological, and physical experience of sudden and unexpected death is not the dreadful event that people might suppose, even in the presence of severe traumatic injury, with or without an NDE.

\section{The Accident Study}

\section{Methods}

I approached 110 patients from an internal medicine and cardiology practice at the end of consecutive, regularly-scheduled office visits for routine medical care. I asked each whether he or she could clearly recall having survived a serious, life-threatening accident for which there was no pending litigation. The litigation exclusion was to avoid "compensation neurosis," which has been found to influence selfreport of accident injuries (Comes, 1992). I also excluded minor motor vehicle accidents.

Forty-six patients recalled one or more qualifying accidents and were recruited for the study. I also recruited three additional serious accident survivors from my previous research: a pilot who fell 15,000 feet into the ocean from a burning aircraft, a Vietnam veteran with a battlefield injury, and a flight attendant who survived a terrorist attack. For the five participants recalling more than one 
qualifying accident, I included only the most severe in each category, such as accidents involving motor vehicles, near-drownings, aircraft, or other circumstances. I obtained written, informed consent from all participants.

During tape-recorded, follow-up interviews, participants gave detailed narratives of the accidents, including duration (that is, estimate of time elapsed between initial realization of imminent danger and completion of accident), loss of consciousness, and hospital treatment. They also reported their position in motor vehicle accidents (that is, driver or passenger) and an estimate of the terminal closing speed between the participant's vehicle and the object of impact.

Participants described all physical injuries received during the accident, and estimated threat to life using a self-report version of the Abbreviated Injury Scale (AIS), a widely-used, injury-severity instrument that measures immediate threat to life on a 0 to 6 scale (Committee on Injury Scaling, 1985). I used for this study the highest AIS value of all injuries - the maximal (MAIS) value - as single injury scores such as the MAIS predict mortality better than scores based on multiple injuries (Kilgo, Osler, and Meredith, 2003). MAIS scores predict survival rates of 100 percent for MAIS 0 , indicating no injuries; 93 percent for MAIS 1 , indicating "minor" injuries such as abrasions, facial lacerations, and arm contusions; 99.6 percent for MAIS 2, indicating "moderate" injuries, such as multiple fractured ribs, fractured collar bone, concussion with loss of consciousness, or facial trauma with loss of four teeth; 98 percent for MAIS 3 , indicating "serious" injuries, such as broken back requiring body cast for 6 weeks, near-amputation of life leg, bilateral femur fractures, or compound fractures of both legs; 94 percent for MAIS 4, indicating "severe" injuries involving massive organ injury; 73 percent for MAIS 5 , indicating "critical" injuries involving a spinal cord syndrome or crushed limb; and 16 percent for MAIS 6, indicating "fatal" injuries such as a crushed skull or chest (Clarke, Ragone, and Greenwald, 2005).

Persons with MAIS 1 injuries had a higher mortality rate than those with MAIS 2, 3, or 4 because those dying without diagnostic workup or autopsy were coded on the basis of external injuries only, which led at times to an artificially low MAIS score (Clarke, Ragone, and Greenwald, 2005). Moreover, the MAIS, which is based on detectable morphologic derangement, does not recognize nonanatomic, physiologic injuries such as intoxication, submersion in water, and suffocation (Adams and 
Carrubba, 1998). To correct for this in estimating threat to life, I used a modified version of MAIS in two cases: one case of transient suffocation from strangulation with minimal abrasion to the neck and another with loss of consciousness from inhalation of toxic fumes with minor superficial burns. I upgraded threat to life in both of these cases from MAIS 1 to MAIS 3 levels.

Participants scored their level of physical pain at the moment of injury on a scale of 0 (no pain) to 10 (worst pain ever felt), and again at its (later) maximal intensity. I measured participants' perception of life threat by asking: "During the accident how certain were you that you were going to be killed, with 1 being completely certain that you would not be killed and 10 being completely certain that you would be killed?" Each participant scored peritraumatic feelings of peace, fear, and horror as absent, present, or strongly present.

I diagnosed peritraumatic dissociation using the self-report version of the Peritraumatic Dissociative Experiences Questionnaire (PDEQ$\mathrm{SR}$, a widely-used, 10-symptom inventory that is "internally consistent, strongly associated with measures of traumatic stress response, strongly associated with a measure of general dissociative tendencies, strongly associated with level of stress exposure, and unassociated with measures of general psychopathology" (Marmar, 1997, p. 2; see Table 1). I gave each participant explicit written instructions to "Please respond to the items by describing your experiences and reaction at the time of this accident. We are not talking about how you are feeling now; rather, we want you to think back to how you were feeling at the time the trauma was taking place" (Panasetis and Bryant, 2003, p. 564). Participants rated each item on a 5-point Likert scale $(5=$ extremely true; $4=$ very true; $3=$ somewhat true; $2=$ slightly true; 1 = not at all true) according to the extent to which they experienced the symptom.

I calculated the mean item response score across all items on the PDEQ-SR, with possible scores ranging from 1 to 5 . Scores of 1.5 or lower are considered not to represent clinically meaningful dissociation; scores above 1.5 are considered diagnostic of peritraumatic dissociation (Marmar, Weiss, Metzler, and Delucchi, 1996). If physical injury had occurred, I added an eleventh symptom ("I felt surprisingly little or no pain immediately at the time of my injury") and scored it separately.

I analyzed data with Pearson's correlation coefficient using Microsoft Office Excel 2003, using a $p$ value of .05 (two-tailed) as the level of significance. 


\section{Results}

Thirty-four men and 13 women (47 of 49 initial participants) completed the PDEQ-SR and were included in the study. These participants recalled 52 qualifying accidents involving motor vehicles $(\mathrm{N}=38)$, falls $(\mathrm{N}=5)$, near-drownings $(\mathrm{N}=2)$, aircraft $(\mathrm{N}=2)$, or other circumstances $(\mathrm{N}=5)$. Participants in motor vehicle accidents were drivers $(N=27$ ), front seat passengers $(N=9)$, or back seat passengers $(\mathrm{N}=2)$. Age at the time of the accident ranged from 8 to 70 years (mean $=34$ ) and at time of interview from 41 to 82 years (mean $=62$ ). Duration of the accident ranged from less than 1 second to 1320 seconds, with 83 percent lasting 10 seconds or less. Terminal closing speed in motor vehicle accidents ranged from 20 to 100 miles per hour (mean $=50$ ).

Thirty-one accidents ( 60 percent) resulted in physical injury and 23 (44 percent) in hospital treatment. Loss of consciousness resulted from head trauma $(\mathrm{N}=5)$ and breathing toxic fumes $(\mathrm{N}=1)$, and lasted from less than 1 second to 120 seconds. All injuries were rated at a MAIS 3 or less in severity. This relatively infrequent occurrence of severe, critical, or fatal physical injuries is consistent with other general accident surveys (Jeavons, Greenwood, and Horne, 2000; http:// www.me.vt.edu/gabler/publications/Development\%20of\%20Acceleration\% 20Based\%20Injury\%20Criteria_Final2.pdf, accessed 04/18/07).

Peritraumatic dissociation occurred in 43 of the 52 accidents (83 percent). Five peritraumatic dissociative symptoms from the PDEQSR were reported during more than half of accidents: "event seemed to happen in slow motion"; "event seemed unreal, as in dream or play"; "found self acting on "automatic pilot"; "not aware of things that happened"; and "felt confused." As noted in Table 1, the remaining peritraumatic dissociation symptoms were endorsed by 13 to 44 percent of accident victims.

PDEQ-SR scores showed a statistically significant positive correlation with MAIS level of injury $(r=.314, p<.05)$ and with loss of consciousness $(r=.312, p<.05)$; and a nonsignificant positive correlation with hospital treatment $(r=.229, p=.10)$. A positive correlation of PDEQ-SR scores with participants' subjective rating of certainty of death approached significance $(r=.269 ; p=.055)$. As shown in Table 2, none of the remaining demographic and accident variables were significantly associated with PDEQ-SR scores.

Peritraumatic feelings of peace, fear, and horror showed little relationship to minor injuries with MAIS $\leq 2$. As shown in Table 3 , a feeling of peace predominated in those experiencing MAIS 3 injuries. 


\section{Table 1 \\ Peritraumatic Dissociative Experiences Questionnaire - Self-Report Version}

\begin{tabular}{ll}
\hline \multicolumn{1}{c}{ Abbreviated Symptom Description } & Frequency of endorsement \\
\hline Events seemed to happen in slow motion & $\mathbf{8 5 \%}$ \\
Event seemed unreal, as in a dream or play & $67 \%$ \\
Not aware of things that happened & $65 \%$ \\
Found self acting on "automatic pilot" & $60 \%$ \\
Felt confused & $58 \%$ \\
Moments of losing track or blacking out & $44 \%$ \\
Felt disoriented and uncertain where I was & $42 \%$ \\
Felt as if floating above scene as spectator & $35 \%$ \\
Felt disconnected from body or body distorted & $33 \%$ \\
Felt what happened to other was happening to self & $13 \%$ \\
\hline
\end{tabular}

Twenty-six of the 31 injured participants ( 84 percent) experienced no pain (level 0 ) at the time of the injury, yet 27 (87 percent) experienced moderate to severe pain (mean level 6.37) minutes to hours later. All injured participants endorsed the statement "I felt surprisingly little or no pain immediately at the time of my injury," with levels of endorsement at "slightly true" $(\mathrm{N}=1)$, "somewhat true" $(\mathrm{N}=4)$; "very true" $(\mathrm{N}=13)$, and "extremely true" $(\mathrm{N}=13)$.

\section{The Acute Dying Experience}

\section{Peritraumatic Dissociation}

Russell Noyes and Roy Kletti (1977) reported the first scientific study of dissociative symptoms occurring during life-threatening events. They studied 101 survivors (median age $=22$ years) of automobile accidents, drownings, miscellaneous accidents, and serious illnesses using a 40-item questionnaire calling for "yes" or "no" answers to questions concerning their life-threatening experiences and depersonalization, a type of dissociation characterized by a feeling of detachment or estrangement from one's self. Sixty-six percent reported "five or more of these depersonalization symptoms pointing to the extremely frequent appearance of this adaptive mechanism under dangerous circumstances" (Noyes and Kletti, 1977, p. 383). Symptoms 
Table 2

Correlation of Demographic and Accident Variables with Peritraumatic Dissociation Experience Questionnaire Self-Report (PDEQ-SR) Scores

Variable

$\mathbf{r}$

$\begin{array}{ll}\text { Age at time of accident (years) } & -.190 \\ \text { For motor vehicle accident (MVA): } 0=\text { passenger, } 1=\text { driver } & -.127 \\ \text { Subject rating of immediate pain: } 0=\text { none } \ldots .10=\text { worst } & -.076 \\ \text { ever felt } & -.075 \\ \text { Gender: } 0=\text { male, } 1=\text { female } & .016 \\ \text { Interval between accident and interview interval (years) } & .053 \\ \text { Type of accident: } 0=\text { MVA, } 1=\text { other } & .143 \\ \text { Estimated duration of accident (seconds) } & .157 \\ \text { Estimated terminal closing speed for MVA (miles per hour) } & .269(p=.055) \\ \text { Subject rating of perceived certainty of death: } 1=\text { none } \ldots & .229(p=.10) \\ \text { 10=complete certainty } & .312(p<.05) \\ \text { Actual threat to life: } & .314(p<.05) \\ \text { Hospital treatment: } 0=\text { no, } 1=\text { yes } & \\ \text { Loss of consciousness: } 0=\text { no, } 1=\text { yes } & \\ \text { MAIS }{ }^{\mathrm{a}} \text { level of injury: } 0,1,2, \text { or } 3 & \end{array}$

${ }^{a}$ Maximal Abbreviated Injury Scale.

were unaffected by age or gender. Noyes and Kletti concluded that "dissociation between an observing and a participating self was occurring under life-threatening circumstances" (1977, p. 384).

More recently, accident-induced or peritraumatic dissociation has been studied using validated versions of the PDEQ. Carol Fullerton and her colleagues (Fullerton, Ursano, Epstein, Crowley, Vance, TzuCheg, and Baum, 2000) evaluated the experiences of 122 motor vehicle accident survivors using the observer-rated version of this questionnaire, the PDEQ-RV (Marmar, Weiss, Schlenger, Fairbank, Jordan, Kulka, and Hough, 1994), in which "clinicians rated subject responses to symptom probes: $0=$ inadequate information, $1=$ absent, $2=$ subthreshold, and $3=$ threshold. Peritraumatic dissociation was scored as present if at least 1 symptom was scored threshold" (Marmar, Weiss, Schlenger, Fairbank, Jordan, Kulka, and Hough, 1994 p. 268). Philippe Birmes and his colleagues (Birmes, Brunet, Benoit, Defer, Hatton, Sztulman, and Schmitt, 2005) used a French version of the PDEQ-SR to study experiences of victims of motor 


\section{Table 3}

Physical Threat to Life

\begin{tabular}{|c|c|c|c|c|}
\hline & MAIS $^{\mathbf{a}} 0$ & MAIS 1 & MAIS 2 & MAIS 3 \\
\hline Number of cases & 21 & 16 & 9 & 6 \\
\hline \multicolumn{5}{|l|}{ Pain: } \\
\hline Immediate & no injury & $19 \%$ & $22 \%$ & $0 \%$ \\
\hline Later & no injury & $88 \%$ & $89 \%$ & $83 \%$ \\
\hline \multicolumn{5}{|l|}{ Peace: } \\
\hline Absent & $86 \%$ & $87 \%$ & $100 \%$ & $33 \%$ \\
\hline Present & $10 \%$ & $7 \%$ & $0 \%$ & $16 \%$ \\
\hline $\begin{array}{l}\text { Strongly } \\
\text { present }\end{array}$ & $4 \%$ & $6 \%$ & $0 \%$ & $51 \%$ \\
\hline \multicolumn{5}{|l|}{ Fear: } \\
\hline Absent & $81 \%$ & $63 \%$ & $66 \%$ & $67 \%$ \\
\hline Present & $14 \%$ & $13 \%$ & $34 \%$ & $0 \%$ \\
\hline $\begin{array}{l}\text { Strongly } \\
\text { present }\end{array}$ & $5 \%$ & $24 \%$ & $0 \%$ & $33 \%$ \\
\hline \multicolumn{5}{|l|}{ Horror: } \\
\hline Absent & $100 \%$ & $94 \%$ & $100 \%$ & $68 \%$ \\
\hline Present & $0 \%$ & $6 \%$ & $0 \%$ & $16 \%$ \\
\hline $\begin{array}{l}\text { Strongly } \\
\text { present }\end{array}$ & $0 \%$ & $0 \%$ & $0 \%$ & $16 \%$ \\
\hline
\end{tabular}

${ }^{a}$ Maximal Abbreviated Injury Scale.

vehicle accidents $(N=30)$, other serious accidents $(N=9)$, or interpersonal violence $(\mathrm{N}=4)$.

The two most commonly endorsed PDEQ symptoms were the same in the present study and in these two recent studies just mentioned: "My sense of time changed - things seemed to be happening in slow motion" (endorsement range 56 to 87 percent) and "What was happening seemed unreal to me, like I was in a dream or watching a movie or play" (endorsement range 39 to 73 percent). Interestingly, these two symptoms were also the ones most commonly reported by Noyes and Kletti (1977), with each symptom endorsed by 72 percent of their sample of survivors of life-threatening circumstances.

Peritraumatic dissociation was diagnosed in 79 percent or more of participants in the present study as well as the studies by Fullerton and 
colleagues and Birmes and colleagues, despite marked differences among these three studies in the time interval between the accident and the interview (see Table 4). Within The Accident Study itself, PDEQ-SR scores showed no correlation with accident-interview interval $(r=$ .016 ), consistent with the report of others (Zoellner, Alvarez-Conrad, and Foa, 2002). Overall, this consistency of peritraumatic dissociation reporting over time comports with studies suggesting that memories of highly significant events are accurate and remain stable over time (Christianson, 1992; van der Kolk and Fisler, 1995).

\section{Individual Peritraumatic Dissociation Symptoms}

Participants in The Accident Study described clear examples of 9 of the 10 PDEQ symptoms (see Table 1) that are worth examining in detail.

"My sense of time changed - things seemed to be happening in slow motion." This was the most commonly reported symptom in all categories of accidents. While being struck head on during a motor vehicle accident, one man reported:

When she hit me, she was probably doing $45 \mathrm{mph}$. It literally picked my car up, spun it around, and somewhere in the process I smashed the whole windshield with my head. . . I was cut pretty badly.

I hit a telephone pole. I must have been a good 5 to 6 feet off the ground and slid down it. ... That was when time just seemed like it went on forever, from the time she hit me and I hit my head and until I hit the telephone pole and slid down. It just seemed like that went on forever. ... A long slow process which probably didn't last more than a second or two.

During a childhood near-drowning incident, a man remembered being rescued by his father:

He reached in, grabbed me by the hair, and pulled me out. ... I remember the time distortion very well. Afterwards I was talking with my father and told him, even though I was coughing, that time slowed down. He said "Yeah, that happens sometimes."

After stepping on a land mine, a Vietnam veteran felt that "[e]verything slowed down to a point where, like Butch Cassidy and the Sundance Kid at the end of the movie, I saw myself coming out of this." Others felt that "time went very slowly," "time absolutely seemed to slow down," "time seemed to stop," and it "seemed like forever but it had to have been less than a second." 


\section{Table 4}

Comparison of Three Accident Studies

\begin{tabular}{|c|c|c|c|}
\hline & $\begin{array}{c}\text { The Accident } \\
\text { Study }\end{array}$ & $\begin{array}{l}\text { Fullerton, } \\
\text { et al. }\end{array}$ & $\begin{array}{l}\text { Birmes, } \\
\text { et al. }\end{array}$ \\
\hline $\begin{array}{l}\text { Motor vehicle } \\
\text { accidents }\end{array}$ & $74 \%$ & $100 \%$ & $70 \%$ \\
\hline \multicolumn{4}{|l|}{ Study participants: } \\
\hline Number & 47 (in 52 accidents) & 122 & 42 \\
\hline $\begin{array}{l}\text { Age at accident ( } \pm \\
\text { SD) }\end{array}$ & $34.2( \pm 17.4)$ & $35.6( \pm 13.1)$ & $38.3( \pm 13.1)$ \\
\hline$\%$ male & $74 \%$ & $52 \%$ & $44 \%$ \\
\hline$\%$ injured & $60 \%$ & $91 \%$ & $100 \%$ \\
\hline Level of injury: & MAIS $^{c} 3$ or less & not stated & not stated \\
\hline \multicolumn{4}{|l|}{ Interview: } \\
\hline Time after accident & 28 years & $<2$ weeks & 4.5 days \\
\hline Instrument used & $\begin{array}{l}\text { 10-item } \\
\text { PDEQ-SR }\end{array}$ & $\begin{array}{l}\text { 8-item } \\
\text { PDEQ-RV }\end{array}$ & $\begin{array}{l}\text { 10-item } \\
\text { PDEQ-SR }\end{array}$ \\
\hline \multicolumn{4}{|l|}{ PDEQ Results: } \\
\hline $\begin{array}{r}\text { Peritraumatic } \\
\text { dissociation }\end{array}$ & $83 \%$ & $79 \%$ & $>90 \%$ \\
\hline Most common items: & & & \\
\hline Slowing of time & $87 \%$ & $56 \%$ & $73 \%$ \\
\hline $\begin{array}{l}\text { Events seemed } \\
\text { unreal }\end{array}$ & $65 \%$ & $39 \%$ & $73 \%$ \\
\hline $\begin{array}{l}\text { Least common item: } \\
\text { "Felt what } \\
\text { happened to } \\
\text { others was } \\
\text { happening to } \\
\text { self" }\end{array}$ & $11 \%$ & $0.8 \%$ & $21 \%$ \\
\hline $\begin{array}{l}\text { Correlated with } \\
\text { age or gender }\end{array}$ & No & No & No \\
\hline
\end{tabular}

${ }^{a}$ Fullerton, Ursano, Epstein, Crowley, Vance, Tzu-Cheg, and Baum, 2000.

${ }^{b}$ Birmes, Brunet, Carreras, Ducasse, Charlet, Lauque, Sztulman, and Schmitt, 2003.

${ }^{c}$ Maximal Abbreviated Injury Scale.

${ }^{d}$ Peritraumatic Dissociative Experiences Questionnaire - Self-Report.

${ }^{e}$ Peritraumatic Dissociative Experiences Questionnaire - Rater Version. 
"What was happening seemed unreal to me, like I was in a dream or watching a movie or play." One man recalled "disbelief that this was actually happening" during a motor vehicle accident. Another felt during his high-speed motor vehicle accident that

[i]t seemed sorta strange, one of those things like "This really can't be happening." I remember the thoughts that kept going through my head were "This is not real. It's just a dream. This can't be happening. In a second I'm going to wake up and we're going to be traveling down the highway."

And while skidding out of control into oncoming traffic, a woman reported: "It was all so surreal at the time because you really don't believe this is happening."

A Marine pilot fell 15,000 feet into the Pacific Ocean after his parachute failed to open after he jumped from a burning aircraft. $\mathrm{He}$ experienced peritraumatic dissociation scoring 2.8 on the PDEQ-SR during this 2 minute and 24 second freefall at speeds of 75 to 80 miles per hour:

The only way I can describe it is if you had the most vivid dream that you ever had in your entire life, just absolute vivid dream, and somebody just shakes you awake and you realize you have gone from one plane to the next. ... That was the strangest feeling that I have ever had ....

"I had moments of losing track of what was going on - I 'blanked out' or 'spaced out' or in some way felt that I was not part of what was going on" and "I was surprised to find out afterward that a lot of things had happened at the time that I was not aware of, especially things I ordinarily would have noticed." Thirty-four participants endorsed one or both of these symptoms in the absence of physical loss of consciousness, suggesting a psychological lapse of awareness. Such was the case with a man after being distracted while riding his bicycle at high speed down a steep grade:

When I turned back to the road, there was a curve at that point and I knew that as fast as I was going down that hill that I would not be able to make that curve. . . . I thought to myself that I had to get my hands out because I knew that I was going to go down.

Within a period of one or two seconds, as soon as I made that conscious decision to tuck my head in and to get my hands out in front of me, my mind went completely blank. I just totally blacked out. When I did wake up was when I hit the ground on my back mainly on my right side. . . . Everything seemed to go black although I guess I didn't lose consciousness because I hadn't hit the ground yet. 
"I found that I was on 'automatic pilot' - I ended up doing things that I later realized I hadn't actively decided to do." A feeling that movements or thoughts were mechanical or automatic was described during a near-fatal motor vehicle accident:

It was raining and I was driving a Volkswagen Beetle. I was going about 80 and I had just passed somebody. ... The next thing I knew, my car was going in circles down the road. I couldn't gain control of it and it ended up going across the two lane road.

From the time I started spinning until the time it wound up on its side, it took maybe 4 seconds. . . I had already determined that the situation was out of my control. I was not even trying to steer anymore.

I had a very heightened sense of awareness. It almost felt like someone else was driving, like someone else had taken over me for that very brief period of time. . . . It was at this point I was strictly a passenger in my own car. ... I was very certain that I would be killed. ... It was a very strange sensation.

"I felt confused; that is, there were moments when I had difficulty making sense of what was happening" and "I felt disoriented, that is, there were moments when I felt uncertain about where I was or what time it was." Most participants in The Accident Study described their $\mathrm{ADE}$ being, as one man put it, "very clear, very logical, very methodical." During taped interviews, the words "confused" and "disoriented" were used only once in descriptions of an ADE. A man recalled his experience after losing control of his car:

It just rolled down the slope of the embankment. The car rolled on its side. ... I was a little disoriented. I was looking out the front windshield and I could see dirt, ground. I didn't realize that I was upside down. As I looked out the front window and saw this dirt I said "Hmmm, that's not correct. That's not right. I must be upside down." I didn't have a sense of being upside down until I knew I was.

Following life-threatening falls, alpine mountain climbers reported ADEs in which "[n]o confusion entered at all" (Heim, 1892, trans. in Notes and Kletti, 1972, p. 47).

The frequent endorsement of these two items regarding confusion and disorientation may reflect the difficulty and confusion resulting from attempts to integrate the dissociative experience mentally into an everyday sense of reality. Bruce Greyson noted that "emotional problems may arise from the difficulty in integrating them into the individual's usual consciousness" (2000, p. 463). As one survivor in 
Noyes and Kletti's study described it, the experience was "not a part of reality. It is hard to explain" (1977, p. 380).

"I felt as though I were a spectator watching what was happening to me, as if I were floating above the scene or observing it as an outsider" and "There were moments when my sense of my own body seemed distorted or changed. I felt disconnected from my own body, or that it was unusually large or small." A sense of detachment or separation from physical body was felt by this woman during a motor vehicle accident:

I was in the passenger side of a new Corvette. The top was down on the car and my boyfriend was driving. We were going around a curve about 60 on a four lane highway, not divided. We went into a skid because the brakes locked. There was nothing he could do. We slid across the oncoming traffic and missed all of it. I remember seeing the cars coming towards us and the feeling of the skid. .. .

The car went down in the ditch, hit the side of the ditch on the left and came back and turned over spanning the ditch. I was under the car in the ditch. I was pinned at the chest. I was not able to get out.

As this was going on, it was kinda like my emotions were suspended and I was an observer. I was detached like I was watching a movie.

The driver of a car who barely missed hitting a sports car that had suddenly cut in front of him experienced a similar reaction:

I was going about 50 miles per hour. ... It cut across several lanes in front of me and I kinda jerked the wheel. ... The pickup truck I was driving started to spin around. When it stopped, I basically T-boned a retaining wall head on. It took 5 to 7 seconds for the whole thing. It was very quick. . . . It was sorta like I was looking at it and I wasn't attached to it. I was an observer. Like it was happening to somebody else. ... . I was just observing it. It was like I was watching it on a monitor or something.

The Marine pilot whose parachute failed to open after he jumped from a burning aircraft recalled:

I was falling and working with the chute and just like that (snap of finger) I was 15 or 20 feet away watching me struggling. It was back and forth - bam, bam - here and then here and then here.... Two or three different times. I was there pulling on the risers and doing this and the next thing I know I was 15 feet away watching myself do it.... I just remember "In, out, in, out." Two or three times.... It was real as could be.

During a terrorist attack that turned Pan American World Airways flight 110 into a burning inferno on December 17, 1973, this flight attendant sought refuge in the only two seats not yet on fire: 
I crawled onto them. . . . That's when I had my experience. It was just all light. It was just incredible happiness and joy! It was indescribable. I saw myself. I was lying there in my uniform. I could see myself clearly through the smoke and I thought "Why aren't I moving?" There was fire everywhere. I thought "Why, why aren't I moving?" But I really didn't care because I was so happy where I was. . . .

And I am looking at myself and I'm lying there with my eyes closed because I couldn't breathe. All of a sudden a passenger screamed "Open the window. Somebody open the window. Help me!" I thought "I have to help that lady." The next thing I knew, I was back in my body.

"I felt as though things that were actually happening to others were happening to me - like I was being trapped when I really wasn't." This least-endorsed symptom was reported during 6 motor vehicle accidents. Three of these endorsements were at the minimally positive level of "slightly true." This symptom was not mentioned during taped interviews in The Accident Study, was not reported by Noyes and Kletti (1977), and was endorsed by only 1 of 122 participants $(0.8$ percent) in the study by Fullerton and colleagues (Fullerton, Ursano, Epstein, Crowley, Vance, Tzu-Cheg, and Baum, 2000). In the original description of the PDEQ, this item had the weakest relationship ( $r=$ .41) with total score of the questionnaire (Marmar, Weiss, Schlenger, Fairbank, Jordan, Kulka, and Hough, 1994).

This was also the least-reported item in the study by Birmes and colleagues' study (Birmes, Brunet, Benoit, Defer, Hatton, Sztulman, and Schmitt, 2005). These researchers found that "deleting item 7 led to a more cohesive factor structure and increased the alpha [that is, internal consistency] by roughly $1 \%$ point." They concluded "that item 7 . . taps onto a different or less frequent experience than the other items" (Birmes, Brunet, Benoit, Defer, Hatton, Sztulman, and Schmitt, 2005, p. 149).

\section{Hyperarousal}

Participants in The Accident Study frequently described an acceleration and sharpening of physical, mental, and visual perceptions consistent with the psychological state of hyperarousal. Perceived slowing of environmental time often accompanied these symptoms.

During the two seconds prior to a head-on collision with an oncoming Buick, a man perceived incredible visual detail: 
It seemed like an eternity to me. ... I could see detail. I recall studying the hood of the old Buick he was driving. The emblem on an older Buick has three shields on it. I could almost count the ribs going across the shields themselves. I saw the little band of stars with little ribs on them.

What really catches my mind today more than anything is the first slat on his grille which was a horizontal slat on a grille. I could see through that and see the actual ribs of the radiator. I just remember that because to me they were not perpendicular, they were somewhat slanted like the radiator was in sideways or cockeyed. I will always remember the emblem and the ribs in that radiator turned just a tad off horizontal.

He was holding the wheel tight and turning. The older cars had a very large steering wheel. I could see the white knuckles holding the steering wheel. . . . Those things I remember more than anything.

A Vietnam veteran experienced acceleration of mental, physical, and visual perceptions after stepping on a land mine:

I took the next step with my right foot and when I did it happened. Everything slowed down to a point where, like Butch Cassidy and the Sundance Kid at the end of the movie, I saw myself coming out of this. I could feel myself being picked up, lifted out and in midair I could actually see coming out of the corner of my eyes this grey cloud. It was the outer perimeter of the fireball. I could feel my ear being blown open. I could feel my hand being released around the rifle. When I landed, I landed on my right side in a complete flat position. The first thing that $I$ saw after it had cleared was Rick getting into a half crouching position. I could see him half way down. What took like that [snap of the finger] to happen, all of this occurred.

During his 15,000-foot free fall into the Pacific Ocean, the Marine pilot whose parachute failed to open reported vivid and detailed visual perception in his "out-of-body" state:

I was falling and working with the chute and just like that [snap of the finger] I was 15 or 20 feet away watching me struggling. I could remember vividly my orange flight suit, my helmet was yellow and had three big blue diamonds stenciled on it. . . . I can remember vividly seeing my boots. I had thought that I had boondockers on, low boots that we normally wore, and was surprised that I had on these brown high topped boots. I thought that that was just not right and it was in fact right. I did have on the high top boots. ... The colors were vivid. It is almost like having an extremely vivid dream. I have never experienced it before or since.

Other typical comments included: "No longer than it took, I sure did think a lot"; and "I do remember a lot of the details for something that 
happened in such a brief period of time, like my thoughts were speeded up."

\section{Predictors of Dissociation}

Markers for severity of peritraumatic dissociation in The Accident Study included perceived threat to life as measured by participants' subjective rating of the certainty of death and actual threat to life as measured by MAIS level of injury, loss of consciousness, and hospital treatment. The threshold for peritraumatic dissociation was reached in 83 percent of participants. As shown in Table 2, participants' subjective rating of certainty of death and actual threat to life were associated (to varying degrees) with depth of peritraumatic dissociation.

As shown in Table 3, participants with MAIS 2 or less injury most commonly experienced an absence of peace, fear, or horror. This pattern comports with Noyes and Kletti's finding of a "blunting or absence of emotion" in 56 percent of their sample while facing lifethreatening danger $(1977$, p. 378). Typical descriptions from The Accident Study include: "I don't remember feeling fear. The word peaceful is not the one I'm thinking of. What I am thinking of is more like relaxed"; "[I remember] being really very calm and saying 'Hmmm. So this is what it is like to die? It's not so bad"; "I felt neutral - not scared"; "It was just so relaxing it was hardly anything I can describe. It was pretty close to peaceful but not from the standpoint I would call it that. More like a floating situation that I went into"; "I don't remember being afraid. It was kinda like my emotions were suspended and I was an observer"; and "I pretty much felt just a lack of emotion, like you were just involved with something and just had to ride it out."

In participants with MAIS 3 injury, peace, fear, and, to a lesser degree, horror were more evident. Similar to the findings of Noyes and Kletti (1976a), when fear and horror were present, these were always the initial emotions, were short-lived, and were followed by a feeling of peace of equal or greater intensity. This woman in The Accident Study gave a typical description:

Our raft overturned. I was trapped in the "V" of the waterfall. I couldn't move or anything. The realization hit me that there is nothing I can do.

The very first reaction was I was terrified for about 2 seconds. Complete terror and panic. After the 2 seconds, I just sorta gave up. I 
remember consciously thinking "there is nothing I can do, just give up."

That's when I started breathing water. I remember the water going down my lungs. There was no pain. I just started breathing water realizing that I was going to die. All I remember was that there was a white light. I didn't see any tunnel or anything. And this extraordinary feeling of total peace. I have never experienced that before - extreme peacefulness. It was just this overwhelming feeling.

I was completely certain that I would be killed. I resigned. I took three or four breaths of water and then it happened - the peace. It just lasted seconds. The next thing I knew was I was above water and they were trying to revive me.

A notable finding that emerged from The Accident Study was the complete absence of physical pain reported by 84 percent of injured participants. In the 16 percent who experienced pain during their accident, this pain was less severe than that felt afterward. During a motor vehicle accident going $\mathbf{4 5}$ miles per hour, a man remembered breaking his right hand and hitting his head on the windshield:

I did not experience any pain at least until a full minute afterwards. There was not much of a sensation of pain at all for the first minute after the accident. Afterwards, it was a 6 or 7 on a scale of 0 to 10 . . . I went to the hospital.

Another man recalled after breaking his collar bone: "I felt no pain when I immediately hit my back, but about 30 seconds later when I got up I had bad pain, a 7 to 8 on a scale of 0 to 10 ."

Still another man recalled no pain during this MAIS 3 injury:

I was jumping out of an airplane during Special Forces training and the static line got caught around my neck. I remember thinking "This is it. I'm dead. There is no way out of this." We called this a "towed trooper." I was towed for not more than 7 or 8 seconds. Time absolutely seemed to slow down. I was completely certain that I would be killed. I gave up. I was not scared at all and experienced resignation at the time. No physical pain. None.

During another MAIS 3 injury, a woman felt no pain when her back was severely broken, an injury that required 6 weeks of treatment in a full body cast.

I was probably going around 40 . . U Up ahead, something alerted me, something caught my eye. I saw something that wasn't normal. I think it was a car fishtailing. It hit the guard rail. . . . From that point it was in the slow motion type thing. . . It was like slow motion. Gray, slow motion. It was just a floating feeling, like floating slow motion. . . . 
It was intensely peaceful. . . At the moment of being thrown out of the car, I felt no pain. Later there was a lot of pain, 9 on a scale of 0 to 10.

Upon impacting the surface of the ocean at " 75 to 80 miles per hour," the Marine pilot whose parachute failed to open suffered two badly shattered ankles, one broken in three places, the other in five, with bone shards protruding though the flesh. Both legs were broken and his pelvis was split. One lung collapsed and three fillings were knocked out of his molars. Later, amputation of both legs was seriously considered. Despite these injuries, he "never felt pain. . . . I knew I was injured badly in the water but it didn't hurt." Later he experienced severe pain, 8 on a 0 to 10 scale.

\section{The Acute Dying Experience with Massive Injury and Suicide}

Would massive physical trauma more severe than that experienced in The Accident Study override the analgesic and emotional effects of peritraumatic dissociation? Consider the experience of a Vietnam veteran who suffered a MAIS 6 injury resulting from an explosion on the battlefield. I had interviewed him in a previous study. His military medical records documented that he

sustained traumatic amputation of the right arm at the humeral joint [shoulder] with transection of the axillary artery and vein and the brachial plexus [severance of all blood and nerve supply to arm.] $\mathrm{He}$ also sustained traumatic amputation of both legs. Bilateral perforation of tympanic membranes [eardrums] with hearing loss was also inflicted ... with open lacerations over trunk, face and left upper extremity. ... [He arrived at the 12 Evacuation Hospital] in shock with no blood pressure. (Sabom, 1982, p. 73)

This veteran recalled the following dying experience during this virtually unsurvivable injury, parts of which I have published previously (Sabom, 1982, pp. 73, 167-168):

I got hit in the right foot. . . . It was almost like in the movies when everything goes super slow motion. I went floating through the air. I remember that from whatever height I was, I was looking down and seeing the battle going on but yet I was floating and tumbling through the air.

When I came down and hit the ground, I remember sitting up and I looked down and I saw my right arm gone and my right leg gone and my left leg was laying off to the left side. I fell back. I remember that very clearly. I couldn't get back up. 
I felt the moistness around my nose and my ears and head and I realized that I was bleeding through the superficial wounds that I had. I laid back and my whole life was just going in front of me like a very fast computer.

I remember that I had always heard and been told that if you die, you really go through three stages before that death sets in. The first one is that you lose your sight, your ability to see. I remember that I couldn't open my eyes anymore and I couldn't see. The second stage was that you would always lose feeling or pressure. You would not feel pain or pressure. I felt no pain. I couldn't feel pressure. The third part is that you would just go into total relaxation and it's over with. Laying there I was thinking about these three things and I realized realistically what I perceived as dying. . . .

... I did believe that I really did die because I am laying there on the battlefield and I came out of my body and I perceived me laying on the ground with three limbs gone. I knew it was me. I recognized it was me. . . . It is a good feeling. I was at total peace with myself because I didn't want to come back. It was different . . I looked like I had three limbs gone and they [the enemy] probably thought I was already dead . ... I I didn't feel anything when I looked at me that way. There was no bad feeling about it. . . . There was no sympathy, there was no sorrow.

Absence of pain from battlefield injuries has been reported in previous wars: "As early as 1946 , Beecher, after observing that $75 \%$ of severely wounded soldiers on the Italian front did not request morphine, speculated that 'strong emotions can block pain"' (van der Kolk, 1994, p. 257). The majority of Israeli soldiers suffering traumatic amputations during the Yom Kippur War "spoke of their initial injury as painless and used neutral terms such as bang, thump, blow etc. to describe their first feeling and often volunteered their surprise that it did not hurt. . . . Furthermore, $24 \mathrm{~h}$ later, all were in considerable pain" (Wall, 1979, p. 259). Thus, peritraumatic dissociation-associated analgesia and emotional anesthesia are capable of blocking the effects of massive, life-threatening trauma.

Would the protective effects of peritraumatic dissociation be present in self-inflicted, life-threatening injuries as well? Only 1 percent of suicidal persons jumping from the Golden Gate and San FranciscoOakland Bay Bridges survive:

The distance at mid-span from rail to water is 250 feet and about 260 feet at low tide and it takes just three to four seconds to travel this distance. The velocity in a free-fall from the Golden Gate Bridge has been calculated to range between 73.6 and 75 miles per hour of impact force in each case. (Rosen, 1975, p. 290) 
For 5 of the 6 jumpers from the Golden Gate Bridge whom David Rosen interviewed,

the fall felt like a long time, from "hours" to "an eternity." ..

The experience of jumping for all six of the survivors was described as tranquil and peaceful and not frightening or terrifying as one might suspect. . . . One survivor said, "It was a good feeling - no screaming. It was the most pleasant feeling I've ever had." . . . One subject stated that he experienced "a sense of relief" and "peace" on the way down. ... Another reported that his descent was "like eternity - beautiful - I enjoyed the sensation." . . All but two of the survivors blacked out just before hitting the water. (Rosen, 1975, p. 291)

A woman who jumped from the San Francisco-Oakland Bay Bridge suffered a fractured pelvis necessitating bed rest for several months. "When she jumped she thought, 'This is the end.' She thought she would die and she did not struggle against it. She felt 'a tremendous sense of peace.' . . . She remembers hitting the water, 'It felt real good . ... I didn't feel hurt"' (Rosen, 1975, p. 293).

Thus, the "protective cocoon," as Brown-Lohr described it, of peritraumatic dissociation appears to prevent both emotional and physical distress during life-threatening trauma, whether accidental or intentional.

\section{Discussion}

The ADE is the experiential continuum lasting seconds to minutes beginning with the sudden, clear perception of threat of significant injury and/or death, followed, at times, by physical trauma, physiological derangement, and loss of consciousness. Swiss geologist Albert von St. Gallen Heim studied this experience in the late $19^{\text {th }}$ century. Heim examined experiences of Alpine climbers during life-threatening falls and found

no anxiety, no trace of despair, no pain; but rather calm seriousness, profound acceptance, and a dominant mental quickness and sense of surety. Mental activity became enormous, rising to a hundred-fold velocity or intensity. . . Time became greatly expanded. (Heim, 1892, trans. in Notes and Kletti, 1972, pp. 46-47)

In reporting his findings, Heim avoided speculative conclusions but offered his report as consolation to the families of mountain climbing 
accident victims. In particular, he noted that the faller, on impact, experienced "No pain! . . . There are easily a hundred such instances that could be cited, all of which prove that in sudden, severe misfortune pain is omitted" (Heim, 1892, trans. in Notes and Kletti, 1972, p. 47).

Psychoanalytic pioneer Oskar Pfister, a colleague of Sigmund Freud, undertook a psychological interpretation of Heim's findings. According to Pfister, Freud believed that

the living organism would be slain by the energy-charged external world were it not equipped with a special protective apparatus [i.e., a stimulus barrier]. We already observe this in the sensory organs, which can admit only very small quantities of stimulation from the external world. External excitation that through its intensity might be able to break through [or invade] the stimulus barrier would be labeled traumatic. ... [Upon such traumatic] stimulus invasions: "Mental life summons cathectic energy from all sides in order to effect countercathexes in the region of the invasion point; and all other psychic systems, particularly perception and decision making, are caught up in this enterprise. Hallucinatory pleasure production is set over the unpleasure cathexis evoked by the frightful surroundings." (Pfister, 1930, trans. in Kletti and Noyes, 1981, pp. 13-14 and 16)

Freud maintained that this "protective shield" against traumatic stimuli was "supplied with its own store of energy" and served "an almost more important function for the living organism than reception of stimuli" (Freud, 1961/1920, p. 27). Pfister proposed that the vivid cognitive and emotional experiences experienced by Heim's fallers, which he called shock thoughts, energized the stimulus barrier "to save the individual from excessive emotional shock" (Pfister, 1930, trans. in Kletti and Noyes, 1981, p. 14).

Noyes and Kletti identified these experiences as "depersonalization in the face of life-threatening danger" and concluded, like Pfister, that "interpretation of depersonalization as a defense against the threat of extreme danger or its associated anxiety seems inescapable" (1977, p. 383). Depersonalization is characterized by "a general dulling or numbing of perception" (Noyes and Kletti, 1976b, p. 26). These acute dying experiences, on the other hand, include features of hyperarousal, involving features of "thoughts sharp or vivid," "thoughts speeded," "vision and hearing sharper" and "altered passage of time."

Hyperarousal reflects "an increased alertness toward a threatening environment" (Noyes and Slymen, 1979, p. 318), particularly in 
situations where the person "found opportunity for emergency action" (Noyes and Slymen, 1979, pp. 319-320):

Were it not for awkwardness of the terminology they might be referred to as "personalizing" effects for, in contrast to the depersonalization that causes an individual to feel empty and lifeless, these stimulating effects are accompanied by a feeling of intense alertness and vitality. (Noyes and Slymen, 1979, pp. 318-319)

Harvey Irwin further observed that self-identity during these experiences remains lucid and intact. According to Irwin, what is altered is not self-identity itself, but

the individual's association of self identity with their physical body, or more precisely, with current bodily sensations. In a life-threatening situation these sensations commonly would include anxiety symptoms and physical pain. [But during these experiences] the experiencer is seemingly oblivious to such sensations. . . . From this perspective, sense of identity and mental imagery appear to be dissociated from physical sensations and (the physical concomitants of) emotions. (Irwin, 1993, p. 97, italics added)

Greyson (2000), in studying dissociative symptoms in NDEs, found that "perception, cognitive functioning, emotional states, and sense of identity may be partly or completely disconnected from the mainstream of conscious awareness," and concluded that NDEs involve "the psychological mechanism of dissociation as a normal response to intolerable trauma" (2000, p. 463).

Trauma-induced dissociation during the ADE has recently been labeled peritraumatic dissociation (Marmar, Weiss, Schlenger, Fairbank, Jordan, Kulka, and Hough, 1994). Elegant research in the animal laboratory offers valuable insight into the neurochemical underpinnings of this complex adaptive experience.

\section{The Perceptual-Defensive-Recuperative (PDR) Model of Response to Predators in Animals}

Consider the response in a natural setting of an animal threatened by a predator. "During the perceptual phase. . . . the traumatic stimulus is detected, encoded and put into memory" (Bolles and Fanselow, 1980, p. 291).

Perceived threat triggers two levels of response. Odors of "reptiles which, under natural conditions exert a limited predatory pressure" on mice, for example, are perceived to be minor, first-tier threats and 
"only induce fear-associated behavioral responses" without release of endorphins (Dell'Omo and Alleva, 1994, p.125). On the other hand, threats perceived to be life-threatening, such as mammalian odors or calls of night-hunting, aerial predators, elicit a higher, second-tier response in mice associated with "instantaneous and reflexlike" release of endorphins (Nijenjuis, Spinhoven, Vanderlinden and van Dyck, 1998, p. 70; see also Hendrie, 1991; Rogers and Hendrie, 1984). Endorphins, in turn, suppress panic and fear (Nijenjuis, Spinhoven, Vanderlinden, and van Dyck, 1998; Siegfried, Frischknech, Nunes de Souza, 1990; van der Kolk, 1994), suppress panic-induced escape behaviors (Kalin, 1993), and induce marked analgesia as what Karen Hollis $(1982$, p. 3) called a "prefigured response" in anticipation of predator-induced, physical injury (Fanselow and Lester, 1988, p. 204).

If predator attack occurs, the defensive phase begins during which the mouse "freezes, or engages in threat displays, or fights back, or runs away, or some way" attempts to survive (Bolles and Fanselow, 1980 , p. 292). Wounds "do not produce pain" (p. 292) since "the primary function of the endorphin analgesic system is to inhibit the pain that would otherwise occur" to allow the mouse to focus on survival strategies (p. 297). If survival efforts fail, endorphin-induced analgesia may ultimately ease the pain of death.

A striking example of these endorphin effects along with its "psychic numbing" (Bandura, Cioffi, Taylor, and Brouillard, 1988; van der Kolk and Saprota, 1991) in a predator-prey interaction, with man being the prey, was reported by David Livingstone who was attacked by a lion in Africa.

Starting and looking half round, I saw the lion just in the act of springing upon me. I was upon a little height; he caught my shoulder as he sprang, and we both came to the ground below together. Growling horribly close to my ear, he shook me as a terrier does a rat. The shock produced a stupor similar to that which seems to be felt by a mouse after the first shake of a cat. It caused a sort of dreaminess, in which there was no sense of pain nor feeling of terror, though quite conscious of all that was happening. . . This singular condition was not the result of any mental process. The shake annihilated fear, and allowed no sense of horror in looking round at the beast. The peculiar state is probably produced in all animals killed by the carnivora; and, if so, is a merciful provision by our benevolent Creator for lessening the pain of death. (Livingstone, 1874, p. 49)

If the mouse survives and danger and fear pass, it enters the recuperation stage during which "there may be pain resulting from 
tissue damage suffered in the attack. It is at this stage that the animal rests, inhibits unnecessary activity, and perhaps engages in more specific recuperative behaviors such as licking its wounds" (Bolles and Fanselow, 1980, p. 292).

Thus, the PDR model predicts a three-stage response to lifethreatening danger: a perceptual stage during which predator threat is perceived and its attack anticipated with a first- or second-tier response, a defensive stage during which endorphin-mediated survival strategies are employed, and a recuperation stage during which the injured prey experiences pain and attends to its wounds. Recuperation may not be necessary, of course, if the prey escapes without injury or dies under endorphin analgesia.

\section{The PDR Response to Threat in Humans}

Humans encountering life-threatening trauma experience a sequence of events remarkably similar to that observed in the threatened animal.

Phase One: Perceptual. Perception of threat is the key traumatic stimulus in humans. Recognizing this, the American Psychiatric Association changed its definition of a potentially traumatizing event from one "outside the range of usual human experience" (American Psychiatric Association, 1987, p. 250) to the "personal experience [i.e., perception] of an event that involves actual or threatened death or serious injury" (American Psychiatric Association, 1994, p. 424; emphasis added).

As in animals, perceived severity of threat determines level of response in humans. Heim (1892) noted in survivors of mountain climbing accidents that

the same person who is able to achieve remarkable acts of this sort [that is, self-rescue] in the face of death will be completely paralyzed by dread in less dangerous situations. $\mathrm{He}$ is no longer able to act so remarkably and is even likely to act in the reverse manner. We conclude that presence of mind arises in response to the highest degree of surprise; in response to a lower degree many persons are, instead, paralyzed. (Heim, 1892, trans. in Notes and Kletti, 1972, p. 47)

Pfister concurred with Heim's observation of a two-tiered human response to different levels of threat:

One would first expect that the reaction to shock would be paralysis of thought and affect. But this happens only where the danger is not 
maximal. Where there is a mild or strong, but not a greatest possible fright, there are degrees of paralysis and speechlessness. But recognition of mortal danger triggers an immense rise in thought production. The rise serves the stimulus barrier in two ways. First, it revises reality and instills a feeling that the danger can be coped with. As a rule this problem is so well resolved that Heim found no evidence of anxiety or pain in $95 \%$ of all climbers who had fallen. . . .

Secondly, shock thoughts separate one from reality. ...

Derealization is like the feeling of being a mere spectator. . . (Pfister, 1930, trans. in Kletti and Noyes, 1981, p. 14)

In The Accident Study, perceived severity of threat was sufficient to trigger this second-tier response of peritraumatic dissociation with endorphin release in 83 percent of cases. Depth of peritraumatic dissociation response as measured by PDEQ-SR scores was associated with participants' perceived certainty of death.

Clarity of threat perception is also important. Following onset of a cardiac arrest in the supine individual, consciousness and electroencephalographic activity persist for 9 to 21 seconds (Aminoff, Scheinman, Griffin, and Herre, 1988; Clute and Levy, 1990; de Vries, Bakker, Visser, Diephuis, and Huffelen, 1998). During this brief conscious interval, terror and pain - not peritraumatic dissociation, peace, and painlessness as found in The Accident Study - are encountered (Dlin, Stern, and Poliakoff, 1974; Dunbar, Warner, and Purcell, 1993; Kowey, 1988; Sabom, 1982, 1988). Perception of life threat in the arrest situation, however, appears ambiguous or absent, even after resuscitation has begun. As one man described it during his cardiac arrest:

I heard the crash cart call for our room and I heard myself saying, "Somebody's made a mistake. This can't be." ... The other guy and I checked the leads to make sure they were still hooked up. And they were. I said, "Well, I wonder why they got this room?" (Sabom, 1998, p. 58)

As resuscitation procedures began, he emphatically protested: "Wait a minute. I want to explain something to you. I don't think you got the right guy" (Sabom, 1998, p. 59).

Another man described a nearly identical scenario:

I hear another Code Blue go off. I am lying there thinking, Who's next?

Suddenly I see these people running into my cubicle. I'm saying, "Not me! Not me!" Obviously they can't hear a thing, but my mind is working. There is all sorts of calamity going on and I'm telling them, "Leave me alone! Leave me alone!" I thought they should be looking after somebody else. (Sabom, 1998, p. 56) 
Thus, clear perception of sudden, life-endangering threat in The Accident Study triggered a peritraumatic dissociation response; whereas ambiguous perception of sudden, life-endangering threat from cardiac arrest is not usually associated with a dissociative experience.

The source of the threat, that is, external in accidents and internal in arrests, and its resulting survival benefit may also make a difference. When the threat is external, peritraumatic dissociation and hyperarousal may aid self-rescue, leading to an adaptive response with positive survival benefit. When the threat is internal, the threat is not clearly perceived nor is self-rescue possible. Moreover, if hyperarousal in the setting of a cardiac arrest were to occur it could actually aggravate the offending arrhythmia and be detrimental to survival (Sabom, 1998, p. 57). The factors responsible for this difference in the $\mathrm{ADE}$ of accident and cardiac arrest victims deserve further study.

Phase Two: Defensive. Once a second-tier response is triggered, psychological and neurochemical defense mechanisms, available at a very early age (Nijenjuis, Vanderlinden, and Spinhoven, 1998), facilitate survival by slowing time, accelerating thought, calming emotions, and blocking the pain of physical injury (Bolles and Fanselow, 1980; Nijenhuis, Spinhoven, Vanderlinden, and van Dyck, 1998; van der Kolk, Greenberg, Orr, and Pitman, 1989).

As shown in Table 2, depth of peritraumatic dissociation correlated positively with markers of perceived threat to life as indicated by subjective rating of certainty of death, and of physical threat to life as indicated by severity of injury, loss of consciousness, and hospital treatment. Feelings varying from absence of emotion to profound peace predominated during these traumatic events.

Noyes and Kletti reported that this "almost universal response to life-threatening danger" occurred "instantly upon the recognition of danger" (1977, pp. 381-382). In The Accident Study, two participants experienced peritraumatic dissociation in less than a second. A man with a PDEQ-SR score of 2.3 ran into the back of a large truck with his motor scooter: "I said 'Oh, crap' and then it was over." Another man scoring 1.9 on PDEQ-SR was the front-seat passenger in a car hit by a garbage truck going 70 miles per hour: "It seemed like forever but it had to have been less than a second." Moreover, Noyes and Kletti reported a mountain climber who "noted that although his fall of 30 feet had not taken long, he found 'ample time in a peculiarly calm 
and impersonal way' to think that he would probably die. 'It is difficult,' he commented, 'to describe the odd third-person viewpoint I seemed to have during the fall"' (1976a, p. 24).

Noyes also reported that many of his survivors of life-threatening circumstances "described themselves as functioning effectively under extraordinary circumstances, aided by a sense of calm objectivity" (1979, pp. 78-79). For the Marine pilot in The Accident Study whose parachute failed to open, momentary panic suddenly ended "as if I had had a shot of something to calm me down." Following this, he "never had any more panic," a state of mind that allowed him to rescue himself from a very difficult and complicated life-threatening situation in a matter of seconds. Heim likewise noted calm presence of mind in mountain climbers during the initial portion of their falls:

Paralyzing anxiety was absent, ideational activity seemed enormously increased, and time seemed drawn out. Judgment remained clear and objective, and as far as external circumstances permitted, the faller remained capable of lightning-quick action. (Heim, 1892, trans. in Notes and Kletti, 1972, p. 47)

Symptoms of hyperarousal - including "thoughts sharp or vivid," "thoughts speeded," and "vision and hearing sharper" - had a high positive correlation, while the symptom of "thoughts blurred or dull" had a high negative correlation, with the overall $\mathrm{ADE}$ (Noyes and Slymen, 1979). Speeding of thought coupled with slowing of time was frequently found in The Accident Study to facilitate survival in emergency situations, as noted above. In some cases, however, these symptoms could be detrimental to survival. Douglas Carson studied this phenomenon in military pilots required to make precisely timed maneuvers in life-threatening situations:

When an individual experiences a temporal distortion, time expands and events appear to happen in slow motion. . . . It seems that the brain instantly becomes intensely alert, increases its efficiency, and begins to process information at an accelerated rate. . . .

These temporal distortions, like spatial disorientations, are particularly dangerous because they are insidious. We tend to believe our perceptions. Our brains, like computers, take in information, process it, and make a decision. That decision is translated into a course of action. If some of the information is erroneous, the decision could be a bad one, and the resulting course of action, particularly in the case of an aviator, may be a fatal one. (1982, pp. 10, 27)

In The Accident Study, one man felt that acceleration of thought and distortion of time were partly to blame for his motor vehicle accident: 
During the whole episode, time seemed to slow down. I can't tell the difference between time slowing down and my thoughts speeding up. One of the problems was that I was trying to turn the wheel too much in my effort to gain control. I think that was one of the reasons I put the rear wheel in the ditch. I overcorrected. It took a long time before the car was responding, so I just kept turning the wheel. I'm sure the time distortion had something to do with me turning the wheel too much.

Survival is also enhanced during a second-tier threat response by an outpouring of endorphins and other, non-opioid substances (Hohmann, Suplita, Bolton, Neely, Fegley, Mangieri, Krey, Walker, Holmes, Crystal, Duranti, Tontini, Mor, Tarzia, and Piomelli, 2005; Yamada and Nabeshima, 1995) that induce analgesia equivalent to 8 milligrams of morphine sulfate, the maximal recommended dose for the severe pain of myocardial infarction (van der Kolk, Greenberg, Orr, and Pitman, 1989).

Dissociation in and of itself may also induce analgesia. Ketamine, a non-opioid anesthetic, works by causing dissociation, which in turn provides analgesia "roughly double that provided by morphine." Ketamine "produces a trancelike state" that in many ways resembles that found during the $\mathrm{ADE}$ :

This state results from an electrophysiologic dissociation between the limbic and higher cortical systems and is termed dissociative anesthesia. Patients sedated with ketamine appear to be awake and have little higher cortical depression. At the same time, however, cortical awareness is blocked from external stimuli, including auditory, visual, or pain-related input. As in a dreamlike state, awareness of time during ketamine sedation is also blunted. Brainstem activity remains normal, and processes for maintaining essential cardiac and respiratory functions are unaltered. (Li, 2005, "Ketamine: Emergency applications," at http://www.emedicine.com/ emerg/topic802.htm, accessed 04/17/07)

As in predator-prey interaction, analgesia occurs when "treatment of the injury does not have the highest biological priority. . . The three obvious high priority behaviours are fighting, escaping and obtaining aid" (Wall, 1979, p. 260).

In The Accident Study, physical pain was completely absent in 84 percent of injured participants and muted in the remainder. This effect occurred at all levels of injury. For example, the Marine pilot whose parachute failed to open sustained multiple severe injuries upon impact with the ocean. Top priority at that moment was obtaining aid and staying afloat. Consequently, "until the time they picked me up, I never felt pain." Following a bad knee injury in a 
motor vehicle accident, a man painlessly fled the scene of the accident to obtain aid:

I tore up my right knee and cut my forehead and my nose and landed outside the car. I tore the anterior ligament of my knee. . . . Afterwards, I was scrambling up the embankment for 5 minutes or so because my knee was not stable and I kept falling back down. Within a few minutes, the ambulance was there. I experienced no pain at the time of the accident, but 4 hours later it began to hurt. Prior to that, the knee felt funny and wasn't supportive. But it didn't hurt.

Hitting one's thumb with a hammer is quite a different experience, however. Here pain is instant and severe:

In what way does this injury differ from a painless injury? My interpretation is that the only possible relevant biological action is to nurse and treat the injured tissue. This action takes precedence over all other possible actions in the victim's repertoire. The victim fully understands and controls the causes of his injury. There is no escape needed, there are no known unexpected dangers and repetition will not occur. Attention and behaviour are now completely monopolized by caring for the injury [that is, recuperation].... (Wall, 1979, p. 260)

As survival strategies fail and death appears imminent, peritraumatic dissociation "may serve as a means of psychological escape when physical escape is not possible" (Gershuny, Cloitre, and Otto, 2003, p. 164). "At the point of surrender, fear subsides and a feeling of tranquility, often profound, develops. With the end of uncertainty, anxiety falls away and the event of death itself is faced with calm" (Noyes, 1972, p.178).

These final feelings were experienced by Brown-Lohr when she realized "this is how I'm going to die" and then encountered "the most incredibly peaceful moment Ive ever known, that I was in no pain. I had no fear anymore, it was total peace" (Survival in the Sky, 1996; emphasis added). And when a drowning woman in The Accident Study realized "there is nothing I can do, just give up," she experienced no pain and an "extraordinary feeling of total peace. I have never experienced that before - extreme peacefulness. It was just this overwhelming feeling."

Following this profound feeling of peace during the acute dying experience, the person may experience a transcendental or mystical experience, that is, an NDE. The point at which the acute dying experience transitions into an NDE is difficult to pinpoint since their symptoms overlap within a rapidly-developing, continuous experience. Heim noted in his sample of mountain climbers that early in a fall 
dissociation and hyperarousal characteristic of the acute dying experience occurred. Later in the fall, when death appeared certain, the faller "often heard beautiful music and fell in a superbly blue heaven containing roseate cloudlets" (Heim, 1892, trans. in Notes and Kletti, 1972, p. 470). According to Noyes and Slymen, this transcendental phase

seemed to involve exclusion of the surrounding environment from awareness. Intense visual imagery appeared in its place giving rise to hallucinatory phenomena in some instances. The more frequent appearance of most of these effects, when death seemed imminent, suggests that a mystical state of consciousness represents a more complete withdrawal from extreme circumstances. (1979, p. 315)

This mystical extension of the $\mathrm{ADE}$ is associated with extreme peace and painlessness. I did not encounter it in The Accident Study but I have found it in more severe, life-endangering accidents and cardiac arrests (Sabom,1982,1998). This comports with Noyes and Kletti's observation "that the mystical extension of this experience occurred almost exclusively in persons in whom some alteration in cerebral functioning might be presumed to have occurred" (1976a, p. 25).

Phase 3: Recuperative. During recuperation following injury, humans like animals are "best served by pain-motivated behaviors and the inhibition of other behaviors" (Bolles and Fanselow, 1980, p. 292). "Nociception subsequently evokes recuperative behavior" (Nijenhuis, Vanderlinden, and Spinhoven, 1998, p. 247). Pain is felt for the first time. This response is nicely illustrated in The Accident Study, in which 87 percent experienced pain for the first time not during the injury itself but only later during recuperation.

In The Accident Study, participants expressed surprise at their lack of fear and pain during their traumatic encounter. After rolling his car, a man recalled: "Fear didn't really set in until the next day when I realized after seeing the car what I had really experienced. Wow, that was a scary moment!" Following a serious auto accident, another man commented: "I was not at all afraid at that time. I had no discomfort. I was just observing it .... Later, when it was over, I took a hard look at it and realized what had just happened and that I had not been horrified." Still another man reflected following a head-on collision: "After it was over and after I got all the boys out of the car and made sure everybody was OK, then it dawned on me that 'Hey, these people could have been really hurt."' 
According to John Gibbs, experiencing "surprise, shock, or puzzlement" following a traumatic experience such as those described "may mean the discovery of profound knowledge about the self or reality" important not only for "individual human cognitive development but also for the collective development of science" (1997, p. 273). Fear and horror are commonly expected during a life-threatening situation but, like pain, they are held off by the adaptive mechanism operative in the $\mathrm{ADE}$. Surprise at this unexpected result leads to questioning preconceived notions of what dying may be like.

Survivors following a major train disaster reported similar behavioral responses. "The reaction of most individuals immediately after the crash was one of numbness, unreality and of almost detached calm. . . Panic was notable by its infrequency" (Boman, 1979, p. 463). Minutes to hours later, "the survivors' mental state changed. They often cried uncontrollably, felt extremely fearful, and found the horror of what they had been through and their narrow escape from death beginning to dawn on them" (Bowman, 1979, p. 464).

The overwhelming emotion and pain often experienced after the threat has passed marks the end of the $\mathrm{ADE}$ and the beginning of the recuperative process. Dissociative and hyperarousal aspects of the $\mathrm{ADE}$, however, may carry over into, or become manifestations of, an acute stress disorder during the first month following the trauma, or posttraumatic stress disorder months to years later. These psychiatric disorders contain symptoms - no longer adaptive, but now pathologic of both dissociation, such as "a subjective sense of numbing, detachment, or absence of emotional responsiveness," "derealization," "depersonalization," and "dissociative amnesia" (American Psychiatric Association, 2000 , p. 471), and hyperarousal, such as "difficulty sleeping, irritability, hypervigilence, exaggerated startle response" (American Psychiatric Association, 2000, p. 472; Marmar, Weiss, Schlenger, Fairbank, Jordan, Kulka, and Hough, 1994; R. Noyes, personal communication, February 8, 2007). Further discussion of these delayed psychiatric symptoms lies outside the scope of this essay.

\section{Summary and Conclusion}

This essay defines the ADE and its subjective psychological and physical manifestations. These occurred instantaneously upon the sudden, clear perception of threat of significant injury and/or death and were followed, at times, by physical trauma, physiological 
derangement, and loss of consciousness. Peritraumatic dissociation, measured by the PDEQ-SR, deepened with increasing levels of perceived threat and physical injury. Hyperarousal - for example, speeding thought, narrowing and sharpening perception, and preparation for action - facilitated self-rescue. A feeling of calm and peace held potentially paralyzing emotions in abeyance. Physical analgesia, induced by endorphins and dissociation in and of itself, occurred even with massive trauma and allowed for the implementation of defensive and rescue strategies. A mystical or transcendental experience, that is, an NDE, may follow the acute dying experience in severely injured persons on the boundary of death. Once danger passed, the first-time appearance of overwhelming emotion and pain often marked the end of the ADE and the beginning of recuperation.

The ADE mirrors the three-stage response of perception, defense, and recuperation observed during predator-prey interaction in animals. It appears to be an adaptive response promoting survival in the acute situation. However, symptoms of the $\mathrm{ADE}$ may in some individuals be carried over into, or become manifestations of, delayed psychiatric disorders.

Considered together, these findings present an interesting paradox: the more terrifying and traumatic an accident may appear, the more peaceful and painless the accident may be experienced. More than 100 years ago, Heim observed:

Quite certainly it is incomparably more painful in both the feeling of the moment and subsequent recollection to see another person fall than to fall oneself. This is attested to by innumerable narratives. Often the spectator, incapacitated by paralyzing horror and quaking in body and soul, carries away from the experience a lasting trauma, while the person whose fall was watched ... comes away from his experience free of fright and pain. (Heim, 1892, trans. in Notes and Kletti, 1972, p. 51)

Modern-day survivors of acute, life-threatening accidents continue to be surprised at the painlessness, peace, slowing of time, and disconnection from the body experienced at the height of the trauma. One survivor concluded: "One of the things that I learned from it was that time, and all of life, lives in how we perceive it. It may not be as solid as we think." This study has shown that the experience of dying a sudden, traumatic death does not reflect the horror of the scene or extent of physical injury, but is mercifully transformed in the eye of the beholder into a tranquil and painless event. 


\section{References}

Adams, V. I., and Carrubba, C. (1998). The Abbreviated Injury Scale: Application to autopsy data. American Journal of Forensic Medicine and Pathology, 19, 246-251.

American Psychiatric Association (1987). Diagnostic and statistical manual of mental disorders ( $3^{\text {rd }}$ ed., text revision). Washington, DC: Author.

American Psychiatric Association (1994). Diagnostic and statistical manual of mental disorders ( $4^{\text {th }}$ ed.). Washington, DC: Author.

American Psychiatric Association (2000). Diagnostic and statistical manual of mental disorders ( $4^{\text {th }}$ ed., text revision). Washington, DC: Author.

Aminoff, M. J., Scheinman, M. M., Griffin, J. C., and Herre, J. M. (1988). Electrocerebral accompaniments of syncope associated with malignant ventricular arrhythmias. Annals of Internal Medicine, 108, 791-796.

Bandura, A., Cioffi, D., Taylor, C. B., and Brouillard, M. E (1988). Perceived self-efficacy in coping with cognitive stressors and opioid activation. Journal of Personality and Social Psychology, 55, 479-488.

Birmes, P., Brunet, A., Benoit, M., Defer, S., Hatton, L., Sztulman, H., and Schmitt, L. (2005). Validation of the Peritraumatic Dissociative Experiences Questionnaire selfreport version in two samples of French-speaking individuals exposed to trauma. European Psychiatry, 20, 145-151.

Birmes, P., Brunet, A., Carreras, D., Ducasse, J., Charlet, J., Lauque, D., Sztulman, H., and Schmitt, L. (2003). The predictive power of peritraumatic dissociation and acute stress symptoms for posttraumatic stress symptoms: A three-month prospective study. American Journal of Psychiatry, 160, 1337-1339.

Bolles, R. C., and Fanselow, M. S. (1980). A perceptual-defensive-recuperative model of fear and pain. Behavioral and Brain Sciences, 3, 291-323.

Boman, B. (1979). Behavioural observations on the Granville train disaster and the significance of stress for psychiatry. Social Science and Medicine, 13, 463-471.

Carson, D. M. (1982). Temporal distortions and the ejection decision. Flying Safety, $38(3), 8-10,26-28$.

Christianson, S. (1992). Emotional stress and eyewitness memory. Psychological Bulletin, 112, 284-309.

Clarke, J. R., Ragone, A. V., and Greenwald, L. (2005). Comparisons of survival predictions using survival risk ratios based on International Classification of Diseases, Ninth Revision and Abbreviated Injury Scale trauma diagnosis codes. Journal of Trauma: Injury, Infection, and Critical Care, 59, 563-569.

Clute, H. L., and Levy, W. J. (1990). Electroencephalographic changes during brief cardiac arrest in humans. Anesthesiology, 73, 821-825.

Comes, P. (1992). Return to work of road accident victims claiming compensation for personal injury. Injury, 23, 256-260.

Committee on Injury Scaling. (1985). American Association for Automotive Medicine: Abbreviated Injury Scale, 1985 revision. Arlington Heights, IL: Author.

Dell'Omo, G., and Alleva, E. (1994). Snake odor alters behavior, but not pain sensitivity in mice. Physiology and Behavior, 55, 125-128.

de Vries, J. W., Bakker, P. F., Visser, G. H., Diephuis, J. C., and van Huffelen, A. C. (1998). Changes in cerebral oxygen uptake and cerebral electrical activity during defibrillation threshold testing. Anesthesia and Analgesia, 87, 16-20.

Dlin, B. M., Stern, A., and Poliakoff, S. J. (1974). Survivors of cardiac arrest: The first few days. Psychosomatics, 15, 61-67.

Dunbar, S. B., Warner, C. D., and Purcell, J. A. (1993). Internal cardioverter defibrillator device discharge: Experience of patients and family members. Heart and Lung, 22, 494-501. 
Fanselow, M. S., and Lester, L. S. (1988). A functional behavioristic approach to adversely motivated behavior: Predatory imminence as a determinant of the topography of defensive behavior. In R. C. Bolles, and M. D. Beecher (eds.), Evolution and learning (pp. 185-212). Hillsdale, NJ: Lawrence Erlbaum.

Freud, S. (1961). Beyond the pleasure principle (trans. by J. Strachey). New York, NY: Norton. (Original work published 1920)

Fullerton, C. S., Ursano, R. J., Epstein, R. S., Crowley, B., Vance, K. L., Tzu-Cheg, K., and Baum, A. (2000). Peritraumatic dissociation following motor vehicle accidents. Journal of Nervous and Mental Disease, 188, 267-272.

Gershuny, B. S., Cloitre, M., and Otto, M. W. (2003). Peritraumatic dissociation and PTSD severity: Do event-related fears about death and control mediate their relation? Behaviour Research and Therapy, 41, 157-166.

Gibbs, J. C. (1997). Surprise - and discovery? - in the near-death experience. Journal of Near-Death Studies, 15, 259-278.

Greyson, B. (1998). Biological aspects of near-death experiences. Perspectives in Biology and Medicine, 42, 14-32.

Greyson, B. (2000). Dissociation in people who have near-death experiences: Out of their bodies or out of their minds? Lancet, 355, 460-463.

Heim, A. (1892). Notizen über den Tod durch Absturz [Remarks on fatal falls]. Jahrbuch der Schweizerischen Alpclub [Yearbook of the Swiss Alpine Club], 27, 327-337. (Trans. by R. Noyes and R. Kletti. [1972]. The experience of dying from falls. Omega, 3, 45-52.)

Hendrie, C. A. (1991). The calls of murine predators activate endogenous analgesia mechanisms in laboratory mice. Physiology and Behavior, 49, 569-573.

Hohmann, A. G., Suplita, R. L., Bolton, N. M., Neely, M. H., Fegley, D., Mangieri, R., Krey, J. F., Walker, M. J., Holmes, P. V., Crystal, J. D., Duranti, A., Tontini, A., Mor, M., Tarzia, G., and Piomelli, D. (2005). An endocannabinoid mechanism for stressinduced analgesia. Nature, 435, 1108-1112.

Hollis, K. L. (1982). Pavlovian conditioning of signal-centered action patterns and autonomic behavior: A biological analysis of function. Advances in the Study of Behavior, 12, 1-64.

Irwin, H. J. (1993). The near-death experience as a dissociative phenomenon: An empirical assessment. Journal of Near-Death Studies, 12, 95-103.

Jeavons, S., Greenwood, K. M., and Horne, D. J. de L. (2000). Accident cognitions and subsequent psychological trauma. Journal of Traumatic Stress, 13, 359-365.

Kalin, N. H. (1993, May). The neurobiology of fear. Scientific American, 268(5), 94-101.

Kayser-Jones, J. (2002). The experience of dying: An ethnographic nursing home study. Gerontologist, 42(Special Issue III), 11-19.

Kilgo, P. D., Osler, T. M., Turner, M., and Meredith, W. (2003). The worst injury predicts mortality outcome the best: Rethinking the role of multiple injuries in trauma outcome scoring. Journal of Trauma: Injury, Infection, and Critical Care, 55, 599-607.

Kletti, R., and Noyes, R. (1981). Mental states in mortal danger. Essence, 5(1), 5-20.

Kowey, P. R. (1988). The calamity of cardioversion of conscious patients. American Journal of Cardiology, 61, 1106-1107.

Livingstone, D. (1874). The life and African explorations of Dr. David Livingstone. St. Louis, MO: Valley Publishing.

Lynn, J., Teno, J. M., Phillips, R. S., Wu, A. W., Desbiens, N., Harrold, J., Claessens, M. T., Wenger, N., Kreling, B., and Connors, A. F. (1997). Perceptions by family members of the dying experience of older and seriously ill patients. Annals of Internal Medicine, $126,97-106$.

Marmar, C. R. (1997). Trauma and dissociation. PTSD Research Quarterly, 8(3), 1-6.

Marmar, C. R., Weiss, D. S., Metzler, T. J., and Delucchi, K. (1996). Characteristics of emergency services personnel related to peritraumatic dissociation during critical incident exposure. American Journal of Psychiatry, 153, 94-105. 
Marmar, C. R., Weiss, D. S., Schlenger, W. E., Fairbank, J. A., Jordan, B. K., Kulka, R. A., and Hough, R. L. (1994). Peritraumatic dissociation and posttraumatic stress in male Vietnam theater veterans. American Journal of Psychiatry, 151, 902-907.

Nijenhuis, E. R. S., Spinhoven, P., Vanderlinden, J., and van Dyck, R. (1998). Somatoform dissociative symptoms as related to animal defensive reactions to predatory imminence and injury. Journal of Abnormal Psychology, 107, 63-73.

Nijenhuis, E. R. S., Vanderlinden, J., and Spinhoven, P. (1998). Animal defensive reactions as a model for trauma-induced dissociative reactions. Journal of Traumatic Stress, 11, 243-260.

Noyes, R. (1972). The experience of dying. Psychiatry, 35, 174-184.

Noyes, R. (1979). Near-death experiences: Their interpretation and significance. In R. Kastenbaum (ed.), Between life and death (pp. 73-88). New York, NY: Springer.

Noyes, R., and Kletti, R. (1972). The experience of dying from falls. Omega, 3, 45-52.

Noyes, R., and Kletti, R. (1976a). Depersonalization in the face of life-threatening danger: A description. Psychiatry, 39, 19-27.

Noyes, R., and Kletti, R. (1976b). Depersonalization in the face of life-threatening danger: An interpretation. Omega, 7, 103-114.

Noyes, R., and Kletti, R. (1977). Depersonalization in response to life-threatening danger. Comprehensive Psychiatry, 18, 375-384.

Noyes, R., and Slymen, D. (1979). The subjective response to life-threatening danger. Omega, 9, 313-321.

Panasetis, P., and Bryant, R. A. (2003). Peritraumatic versus persistent dissociation in acute stress disorder. Journal of Traumatic Stress, 16, 563-566.

Pfister, O. (1930). Shockdenken und shockphantasien bei hochster todesgefahr [Shock thoughts and fantasies in extreme mortal danger]. Zeitschrift fur Psychoanalyse, 16, 430-455. (Trans. by R. Kletti and R. Noyes. [1981]. Mental states in mortal danger. Essence, 5[1], 5-20.)

Rogers, R. J., and Hendrie, C. A. (1984). On the role of endogenous opioid mechanisms in offense, defense and nociception. In K. Miczek, M. R. Kruk, and B. Olivier (eds.), Ethopharmacological aggression research: Proceedings of a symposium on psychopharmacology of aggression (pp. 27-41). New York, NY: Alan R. Liss.

Rosen, D. (1975). Suicide survivors: A follow-up study of persons who survived jumping from the Golden Gate and San Francisco-Oakland Bay Bridges. Western Journal of Medicine, 122, 289-294.

Sabom, M. B. (1982), Recollections of death: A medical investigation. New York, NY: Harper and Row.

Sabom, M. B. (1998). Light and death: One doctor's fascinating account of near-death experiences. Grand Rapids, MI: Zondervan.

Siegfried, B., Frischknech, H.-R., and Nunes de Souza, R. L. (1990). An ethological model for the study of activation and interaction of pain, memory and defensive systems in the attacked mouse: Role of endogenous opioids. Neuroscience and Biobehavioral Reviews, 14, 481-490.

Survival in the sky: A wing and a prayer [Video]. (1996). Broadcast December 8, 1996, on The Learning Channel. Distributed by Unapix Home Entertainment: New York, NY.

van der Kolk, B. A. (1994). The body keeps the score: Memory and the evolving psychobiology of posttraumatic stress. Harvard Review of Psychiatry, 1, 253-265.

van der Kolk, B. A., and Fisler, R. (1995). Dissociation and the fragmentary nature of traumatic memories: Overview and exploratory study. Journal of Traumatic Stress, 8 , $505-525$.

van der Kolk, B. A., Greenberg, M. S., Orr, S. P., and Pitman, R. K. (1989). Endogenous opioids, stress induced analgesia, and posttraumatic stress disorder. Psychopharmacology Bulletin, 25, 417-421. 
van der Kolk, B. A., and Saprota, J. (1991). The biological mechanisms and treatment of intrusion and numbing. Anxiety Research, 4, 199-212.

Wall, P. D. (1979). On the relation of injury to pain. Pain, 6, 253-264.

Yamada, K., and Nabeshima, T. (1995). Stress-induced behavioral responses and multiple opioid systems in the brain. Behavioural Brain Research, 67, 133-145.

Zoellner, L. A., Alvarez-Conrad, J., and Foa, E. (2002). Peritraumatic dissociative experiences, trauma narratives, and trauma pathology. Journal of Traumatic Stress, $15,49-57$. 